\title{
ENTOMOLOGY
}

\section{Evaluation of secondary killing effect of Imidacloprid Gel Baits to control Blattella germanica (Linné 1767) (Blattaria: Blattellidae)}

\author{
A. Drago, ${ }^{1}$ E. Giussani, ${ }^{1}$ M. Dutto,${ }^{2}$ S. Martini, ${ }^{1}$ M.L. Vitale ${ }^{1}$ \\ ${ }^{1}$ Entostudio s.r.l., Ponte San Nicolò; ${ }^{2}$ Studio di Entomologia e Fitopatologia Applicata, Verzuolo, Italy
}

\begin{abstract}
Blattella germanica (L.) (Blattodea: Blattellidae) is one of the major household pests worldwide, commonly named German cockroach. Application of gel baits is one of the most efficient management methods. This study investigated the effect of 3 commercially available Imidacloprid gel baits on the palatability of dead cockroaches and, consequently, on the efficacy of secondary killing. German cockroaches killed by the gel baits and others killed by freezing were offered to conspecifics, the numbers of cannibalistic cockroaches and dead cockroaches, as well as weight loss were recorded. Despite the content of Imidacloprid is identical in all the baits, the palatability of the cockroach killed by the gel consumption and used as food was different between the 3 commercial products, with consequences on the secondary killing effect. These results suggest as the bait co-formulants play an important role not only on the palatability of the bait but also in the palatability of the dead cockroaches which are eaten by conspecifics, and therefore, in the result of a pest control application.
\end{abstract}

Correspondence: Andrea Drago, Entostudio s.r.1., Viale del Lavoro 66, Ponte San Nicolò (PD), Italy.

E-mail: drago@entostudio.com

Key words: German cockroach; delayed killing; cannibalism; secondary killing.

Contributions: The authors contributed equally.

Conflict of interest: The authors declare no potential conflict of interest.

Funding: None

Availability of data and materials: All data are available within the text.

Received for publication: 6 June 2021.

Revision received: 26 November 2021.

Accepted for publication: 3 January 2022.

${ }^{\circ}$ Copyright: the Author(s), 2021

Licensee PAGEPress, Italy

Journal of Entomological and Acarological Research 2021; 53:9897 doi:10.4081/jear.2021.9897

This article is distributed under the terms of the Creative Commons Attribution Noncommercial License (by-nc 4.0) which permits any noncommercial use, distribution, and reproduction in any medium, provided the original author(s) and source are credited.

\section{Introduction}

Blattella germanica (Linné, 1767) (Blattodea Blattellidae) is a species native to Southeast Asia. It is one of the major pests in residences, commercial buildings, agri-food industries, and healthcare facilities (Fotedar et al., 1991; Bonnefoy et al., 2008; Pampiglione and Velo, 2010). One of the principal methods of control for $B$. germanica is the application of insecticide baits. These baits are made from active ingredients with low repellency and a matrix food attractant. One of the most common active ingredients used in these baits is Imidacloprid and use of gel bite is recommended for control infestation (Appel and Tanley, 2000; Pampiglione and Velo, 2010; Salehzadeh et al., 2020).

$B$. germanica is an omnivorous insect with a propensity towards necrophagy and cannibalism (Roth and Willis, 1960; Guthrie and Tindall, 1968), which allows insecticide residue to be transferred from a dead cockroach to another that feeds on it (or exposed to the feces and regurgitant from the intoxicated cockroaches) in an event termed "secondary killing" (Gahlhoff et al., 1999; Buczkowski et al., 2001). Effect of "secondary killing" associated to Imidacloprid ingestion is demonstrated in Periplaneta americana (Linné, 1758) (Jaramillo and Gonzalez, 2005).

Cockroaches intoxicated by baits do not die immediately but return to their shelters which expose conspecifics of other life stages (such as first instars and gravid females) that rarely go out of their shelters.

A high number of cockroaches that died from other causes are also available for cannibalism in a heavily infested area, reducing the probability that a cockroach will be in contact and consume a dead conspecific that had been intoxicated by bait. In this study, we investigated the difference in palatability between an insecticide-killed German cockroach and a dead cockroach without any insecticide residue, and the level of secondary killing caused by Imidacloprid gel baits.

\section{Materials and Methods}

B. germanica used in this study were from a colony maintained in the laboratory of Entostudio s.r.l. (Ponte San Nicolò, Padua, Italy) since 2011. The colony was started with cockroaches collected from an infested building in the centre of Padua, no field-collected individuals were added to the colony in the next years. Cockroaches are reared in plastic boxes $(33 \times 23 \times 27.5 \mathrm{~cm})$, with cat litter as substrate and cardboard tubes as shelters. The room is maintained under 
$25 \pm 1{ }^{\circ} \mathrm{C}, 40 \pm 5 \% \mathrm{RH}$, and 12:12 h (L:D) photoperiod. Cockroaches are fed with potatoes and cat biscuits ad libitum.

Three commercially available insecticide baits were tested in this study, all containing 2.15\% Imidacloprid. One of the gels (Gel 2) also contained $0.2 \% \mathrm{~s}$-methoprene but because it is an insect growth regulator (IGRs), likely shouldn't had effect on the results of this study because only adult cockroaches were tested. For each gel, 6 replications were carried out.

This experiment was conducted in a laboratory maintained at $25 \pm 1{ }^{\circ} \mathrm{C}, 40 \pm 5 \%$ R.H. and $12: 12 \mathrm{~h}$ (L:D) photoperiod. The light was $4500^{\circ} \mathrm{K}$ and set at $300 \mathrm{Lux}$. Each gel bait was tested in a different arena to avoid cross-contamination. The arena consisted of a transparent plastic box $(33 \times 23 \times 13.5 \mathrm{~cm})$, with a lid that opened in the centre and was provided with an anti-escape mix $(50 \mathrm{ml}$ of mineral oil; $50 \mathrm{~g}$ of vaselin grease and $30 \mathrm{ml}$ of vaselin oil). A IRLAB PR-T600N video camera (Huihao Industrial Park, Gongming Town, Shenzhen, China) was positioned $50 \mathrm{~cm}$ above each arena, to record the test and be able to measure the feeding behaviour of the insects.

Two main groups of cockroaches were used: $B$. germanica Test (BT) and B. germanica Food (BF). BF are the specimens which were used as food for BT during the test. BF was compound of two sub-groups: B. germanica Food Gel (BFG), which were cockroaches killed by insecticide consumption, and B. germanica Food Without Gel (BFWG), which were cockroaches killed by freezing and thus which never had contact with any insecticide.

BFG were obtained leaving 25 adult males and 25 adult females in an arena without any food or water, with just $0.2 \mathrm{~g}$ of one of the three gels under investigation. For 3 days, dead cockroaches were collected twice a day and frozen at $-18^{\circ} \mathrm{C}$. Dead cockroaches were collected with high frequency to avoid other cockroaches feeding on them and consequently dying due to secondary killing.

BFWG consist in adult cockroaches collected from the colony boxes and frozen at $-18^{\circ} \mathrm{C}$ for 24 hours.

To evaluate the capability of the secondary killing 20 BT adult cockroaches (10 $\widehat{\delta} \hat{\sigma}$ and 10 우) were starved for 3 days in an arena where a cardboard shelter and a Petri dish with water were available. At the end of the starving period both BFs (BFG and BFWG) were defrosted. A part of BFG and BFWG specimens (5 $\widehat{\delta} \widehat{o}$ and 5 우), defrosted and dried with absorbent paper, were placed in two different ventilated Petri dishes. The two Petri dishes with BFG and with BFWG were positioned in the BT arena. The Petri dishes were placed in two adjacent corners on the shorter sides of the arena. The water was placed in the centre of the arena and the shelter on the opposite side of the BF.

The BFs placed into the arena, as food, are named "Internal BF", to distinguish from the "External BF" which are kept outside the arenas but in the same environment where the test was run, to evaluate the natural variation of weight of the defrosted cockroaches.

All Petri dishes (both internal and external ones) were weighed before the test starting.

All the arenas were filmed during the first 90 minutes since the Petri dishes with BFs were placed. This period was decided basing on observations during the normal rearing activities, when baits or food is provided to starved cockroaches. When food is provided to the hungry cockroaches in the colony, they immediately feed and complete the meal within 1 hour. Because the cockroaches are reared in the same conditions as for the test, 90 minutes observation period was decided.

After 24 hours the BFs were provided, the dead BTs were counted, and the "Internal" and "External" Petri dishes were weighed. The videos were analysed counting the number of active cockroaches on BFG and on BFWG every 2 minutes for the first
60 minutes, and every 5 minutes for the remaining 30 minutes. For "Active cockroaches" the individuals feeding on BFs are intended.

This method was implemented separately for each of the three gels.

\section{Statistical analysis}

The mean weight losses of internal BF were compared using the paired two-sample Wilcoxon rank-sum test, to evaluate the consumption of BFG compared to BFWG for each Gel. The twosample Wilcoxon rank-sum test was also used to compare the mean weight losses of internal BF, BFG and BFWG, with the external $\mathrm{BF}$ to evaluate the consumptions of $\mathrm{BF}$ during the test with the natural variation of weight of the defrosted cockroaches.

For each gel, the active cockroaches that were on BFG and on BFWG were compared considering all the counts acquired in time intervals of 10 minutes using the paired two-sample Wilcoxon ranksum test. Statistical analysis was performed in $\mathrm{R}$ version 3.6.1.

The mean numbers of dead cockroaches were compared using the Analysis of Variance (ANOVA), followed by the TukeyKramer test for post-hoc comparison. The software used was CoStat Version 6.400.

\section{Results}

Three categories of data were collected: i) weight losses of BFs internal and external in 24 hours, ii) mean number of active cockroaches feeding on B. germanica Food Gel (BFG) and on BFWG during the first 90 minutes of the test, and iii) number of dead individuals after $24 \mathrm{~h}$.

\section{Weight loss}

The weight loss of each category of BF is shown in Table 1 and 2 and Figure 1. The mean weight losses of BFG and BFWG were compared with each other and singularly with External BF to understand if the weight loss of Internal BF could be ascribed to alimentary consumption or to natural weight loss. During the comparison of Internal BF weight losses (Table 2), the analysis showed no significant differences for each Gel bait between the mean weight loss of BFG and the mean weight loss of BFWG.

Comparing Internal BFs weight losses with those of External BFs, it appears that BFWG of Gel 1 and Gel 3, and BFG of Gel 2 were consumed in a significant amount. Whereas the weight losses of BFG of Gel 1 and of BFWG of Gel 2 were not significant.

\section{Active cockroaches}

Cockroaches behaved in different ways for each of the three cases (Figure 2 and Table 3). In the case of Gel 1, cockroaches were found significantly more frequently on BFWG from the beginning of the test to the $60^{\text {th }}$ minute. Gel 2 showed the opposite situation, with cockroaches significantly more active on BFG in the intervals going from 2 to 50 minutes, and in the interval at 65 -

Table 1. Comparison of the mean weight losses of internal BF, BFWG and BFG, using the paired two-sample Wilcoxon ranksum test.

\begin{tabular}{lccc} 
Test & BFWG, Mean \pm sd & BFG, Mean \pm sd & P-value \\
Gel1 & $0.21 \pm 0.07$ & $0.14 \pm 0.03$ & 0.156 \\
Gel2 & $0.12 \pm 0.03$ & $0.14 \pm 0.2$ & 0.141 \\
\hline Gel3 & $0.18 \pm 0.05$ & $0.15 \pm 0.4$ & 0.498 \\
\hline
\end{tabular}


Table 2. Comparison of the mean weight losses of internal BF, BFWG and BFG with the external BF, the control using the two-sample Wilcoxon rank-sum test.

\begin{tabular}{llccc} 
Test & & Internal BF, Mean \pm sd & External BF, Mean \pm sd & P-value \\
Gel1 & BFWG & $0.21 \pm 0.07$ & $0.10 \pm 0.02$ & $0.016^{*}$ \\
& BFG & $0.14 \pm 0.03$ & & 0.053 \\
Gel2 & BFWG & $0.12 \pm 0.03$ & $0.09 \pm 0.02$ & 0.118 \\
& BFG & $0.14 \pm 0.2$ & $0.015^{*}$ \\
\hline Gel3 & BFWG & $0.18 \pm 0.05$ & $0.08 \pm 0.01$ & $0.004^{* *}$ \\
& BFG & $0.15 \pm 0.4$ & & $0.004^{* *}$ \\
\hline
\end{tabular}

${ }^{*} \mathrm{p}<0.05 ; *{ }^{*} \mathrm{p}<0.01 ; * * * \mathrm{p}<0.001$.

Table 3. P-values obtained comparing the mean active cockroaches on BFG and on BFWG in time intervals of 10 minutes using the paired two-sample Wilcoxon rank-sum test.

\begin{tabular}{|c|c|c|c|c|}
\hline Test & Interval (minutes) & BFWG, Mean \pm sd & BFG, Mean \pm sd & $P$-value \\
\hline Gel 1 & $\begin{array}{c}2-10 \\
12-20 \\
22-30 \\
32-40 \\
42-50 \\
52-60 \\
65-70 \\
75-80 \\
85-90\end{array}$ & $\begin{array}{l}1.90 \pm 2.09 \\
3.53 \pm 2.58 \\
3.90 \pm 1.92 \\
3.67 \pm 2.15 \\
3.13 \pm 2.19 \\
2.47 \pm 1.57 \\
1.25 \pm 1.14 \\
0.83 \pm 0.72 \\
0.75 \pm 0.75\end{array}$ & $\begin{array}{l}0.93 \pm 0.98 \\
1.07 \pm 1.05 \\
1.27 \pm 0.87 \\
0.73 \pm 0.78 \\
0.13 \pm 0.35 \\
0.27 \pm 0.45 \\
1.42 \pm 1.56 \\
0.83 \pm 1.53 \\
1.00 \pm 1.35\end{array}$ & $\begin{array}{c}0.02745^{* *} \\
* * * \\
* * * \\
* * * \\
* * * \\
* * * \\
0.8775 \\
0.8631 \\
0.5687\end{array}$ \\
\hline Gel 2 & $\begin{array}{c}2-10 \\
12-20 \\
22-30 \\
32-40 \\
42-50 \\
52-60 \\
65-70 \\
75-80 \\
85-90\end{array}$ & $\begin{array}{l}0.37 \pm 0.56 \\
0.33 \pm 0.55 \\
0.27 \pm 0.58 \\
0.30 \pm 0.53 \\
0.57 \pm 1.01 \\
0.50 \pm 1.17 \\
0.17 \pm 0.39 \\
0.17 \pm 0.39 \\
0.25 \pm 0.45\end{array}$ & $\begin{array}{l}2.63 \pm 1.90 \\
3.23 \pm 2.10 \\
2.97 \pm 1.59 \\
2.67 \pm 1.86 \\
1.60 \pm 1.79 \\
0.67 \pm 1.18 \\
0.58 \pm 0.79 \\
0.58 \pm 0.67 \\
0.83 \pm 1.03\end{array}$ & $\begin{array}{c}* * * \\
* * * \\
* * * \\
* * * \\
0.0005983 * * * \\
0.2885 \\
0.03689 * * \\
0.1198 \\
0.1427\end{array}$ \\
\hline Gel3 & $\begin{array}{c}2-10 \\
12-20 \\
22-30 \\
32-40 \\
42-50 \\
52-60 \\
65-70 \\
75-80 \\
85-90\end{array}$ & $\begin{array}{c}1.1 \pm 0.71 \\
1.83 \pm 1.09 \\
2.4 \pm 1.19 \\
2.63 \pm 1.19 \\
2.63 \pm 1.40 \\
1.77 \pm 1.28 \\
1.25 \pm 1.14 \\
0.83 \pm 0.72 \\
0.75 \pm 0.75\end{array}$ & $\begin{array}{c}1.2 \pm 1.27 \\
1.53 \pm 1.07 \\
1.7 \pm 1.06 \\
2.00 \pm 1.23 \\
1.50 \pm 1.01 \\
1.67 \pm 1.40 \\
1.42 \pm 1.56 \\
0.83 \pm 1.53 \\
1.00 \pm 1.35\end{array}$ & $\begin{array}{c}0.6673 \\
0.2282 \\
0.04189^{*} \\
0.1294 \\
0.01576^{* *} \\
0.7071 \\
0.8775 \\
0.8631 \\
0.5687\end{array}$ \\
\hline
\end{tabular}

${ }^{*} \mathrm{p}<0.05 ;{ }^{* *} \mathrm{p}<0.01 ;{ }^{* * *} \mathrm{p}<0.001$.

Gel 1

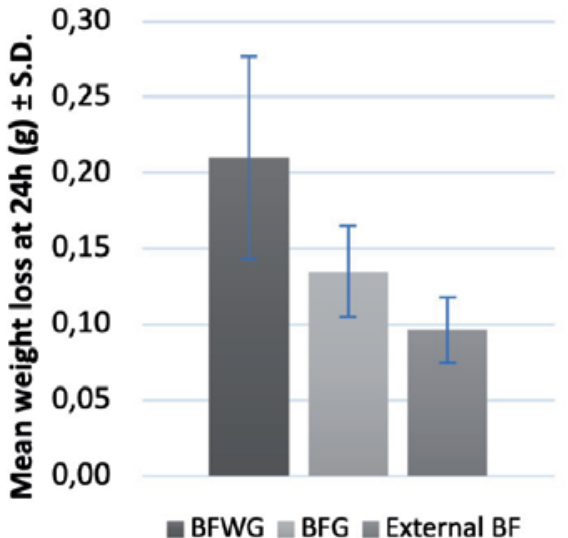

Gel 2

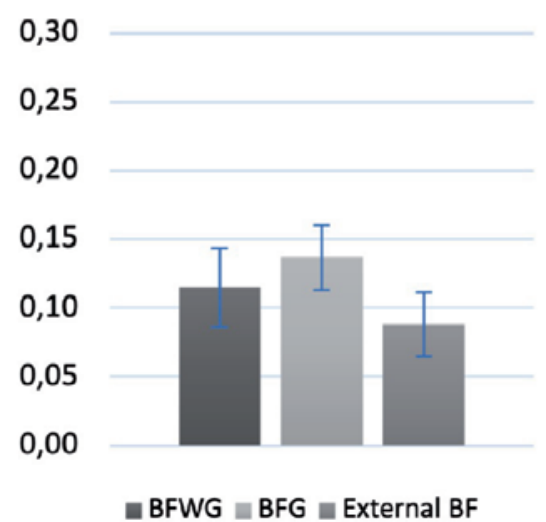

Gel 3

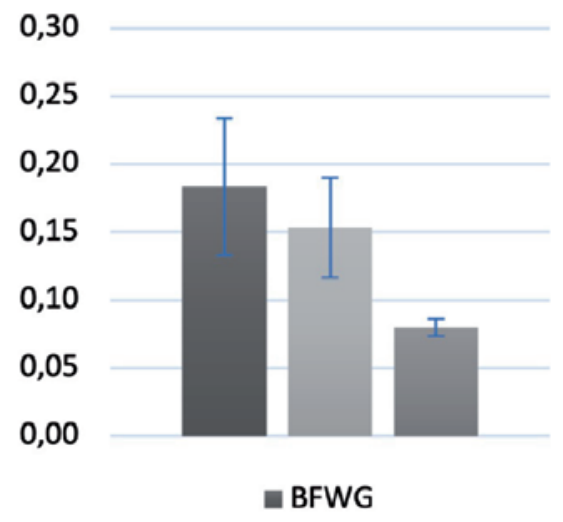

Figure 1. Mean weight losses of BFWG, BFG and External BF. Bars represent standard deviations. 
Gel 1

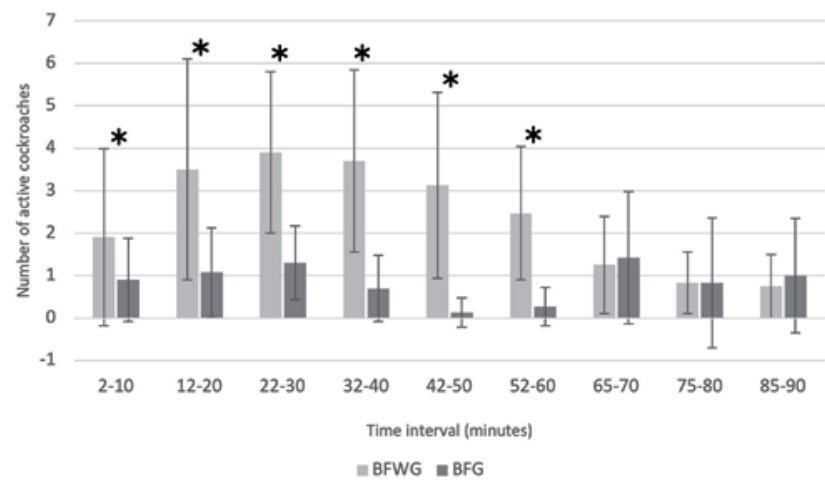

Gel 2

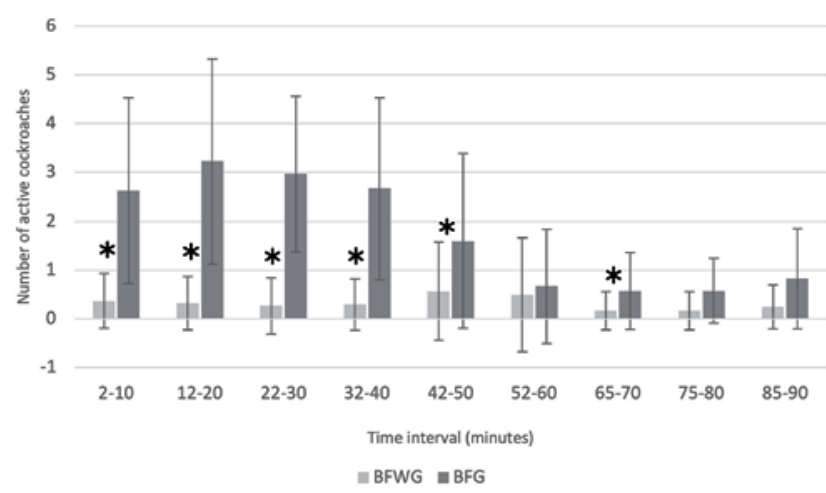

Gel 3

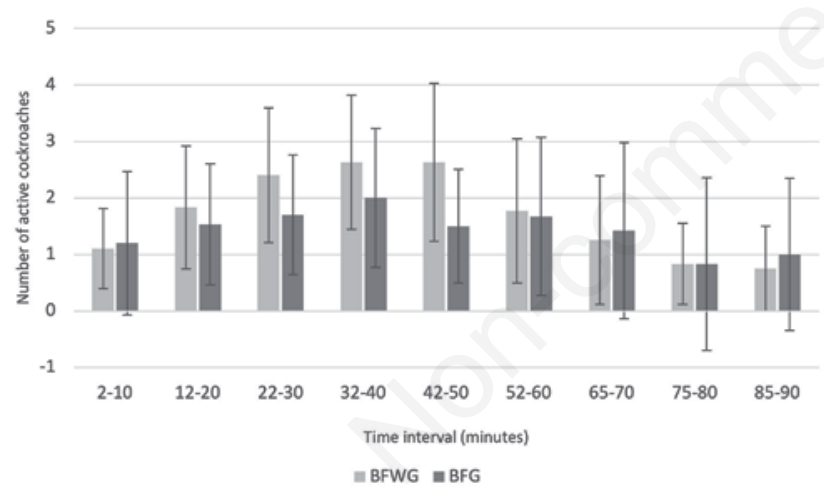

Figure 2. Mean number of active BT on BFWG and on BFG counted at different time intervals. Asterisks indicate significant differences between the number of BT on BFWG and on BFG $(P<0.05)$. Bars represent standard deviations.
70 minutes. Gel 3 exhibited a significant difference for just two intervals, 22-30 minutes and 42-50 minutes, in which cockroaches preferred BFWG.

\section{Death rate after $24 \mathrm{~h}$}

Gel 1 caused the lowest mortality rate of secondary killing after 24 hours (Table 4, Figure 3), with $14.15 \%$ of dead individuals in all replications. Gel 2 and Gel 3 caused $54.15 \%$ and $45 \%$ mortality, respectively (Table 4 and Figure 3 ).

\section{Discussion}

To understand which type of $B$. germanica Food (BF) was preferred by $B$. germanica Test (BT), the frequentation and the consumed amount were both considered. BT behaved differently in each of the three cases. For Gel 1, it seems that BT could distinguish B. germanica Food Gel (BFG) from B. germanica Food Without Gel (BFWG), showing a clear preference for the latter.

In the case of Gel 2, the results were the opposite. When analysing the frequentation data, it appears that $\mathrm{BT}$ preferred $\mathrm{BFG}$; though, the weight loss of BFG, was not significantly different from that of BFWG. A hypothesis for this could be that the cockroaches which fed on BFG quickly get intoxicated, consuming just a small amount. In fact, after 50 minutes there is no significant difference between BTs feeding on the two categories of BFs, except for a single interval (65-70 minutes), in which the number of active cockroaches is very small.

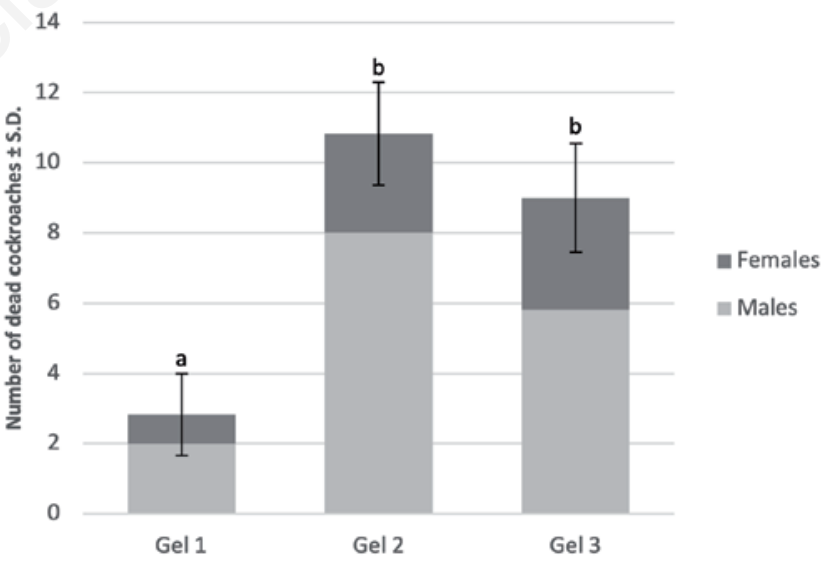

Figure 3. Mean number of dead cockroaches at 24 hours. Significant differences are marked with different letters (ANOVA test, $\mathbf{p}<0,001$; Tukey-Kramer). Bars represent the standard deviations of the mean number of dead cockroaches.

Table 4. Number of dead individuals after 24 hours.

\begin{tabular}{|c|c|c|c|c|c|c|c|c|c|}
\hline \multirow[t]{2}{*}{ Repl. } & \multicolumn{3}{|c|}{ Gell } & \multicolumn{3}{|c|}{ Gel2 } & \multicolumn{3}{|c|}{ Gel3 } \\
\hline & M & $\mathrm{F}$ & Tot & M & $F$ & Tot & M & F & Tot \\
\hline 1 & 2 & 0 & 2 & 8 & 4 & 12 & 7 & 3 & 10 \\
\hline 2 & 2 & 0 & 2 & 7 & 3 & 10 & 6 & 4 & 10 \\
\hline 3 & 2 & 1 & 3 & 9 & 4 & 13 & 8 & 3 & 11 \\
\hline 4 & 2 & 1 & 3 & 10 & 1 & 11 & 4 & 4 & 8 \\
\hline 5 & 1 & 1 & 2 & 7 & 3 & 10 & 6 & 1 & 7 \\
\hline 6 & 3 & 2 & 5 & 7 & 2 & 9 & 4 & 4 & 8 \\
\hline
\end{tabular}


With Gel 3, BT did not distinguish BFG from BFWG, or at least they did not show a strong preference for one group. In fact, the weight losses and the intensity of frequentation were comparable and just during the two intervals of 22-30 and 42-50 minutes a significant difference was detected, with the preference for the BFWG.

The mortality data is the most interesting from the pest control point of view. In the case of Gel 1, the mortality rate was low which is in accordance with the very little BFG consumption. The mortality in the Gel 2 is the higher, even if not statistically significant respect to the Gel 3.

\section{Conclusions}

The study shows how not just the Active Ingredient affects the palatability of cockroaches dead for the assumption of Imidacloprid baits, but co-formulants play a key role too. If a dead cockroach is preferred as food the efficacy of the insecticide intervention is enhanced and even in high infestations with abundant sources of food are available, just one application of bait can be sufficient to control the pest.

The baits should be therefore developed not only evaluating the immediate efficacy but also considering the secondary killing consequences.

The preference of $B$. germanica for cockroaches contaminated or not by insecticides was evaluated in some studies. Durier and Rivault (2000) considered the amount consumed and the study resulted in freeze-killed cockroaches being eaten more $(46.7 \%$ of consumption) than Fipronil (3.5\%) and hydramethilnon-killed ones (12.1\%). Buczkowski (2001) considered instead the frequentation; $68 \%$ of the BT preferred rat chow to BFWG (14\%) and, in another arena, $44 \%$ preferred rat chow to fipronil-killed cockroaches $(38 \%)$.

No papers were found where different baits, and indirectly different co-formulants composition, were compared in the palatability of the dead cockroaches.

More studies should be done to evaluate the palatability of other baits and active ingredients, toward other species of infesting cockroaches too.

\section{References}

APPEL A.G., TANLEY M.J., 2000 - Laboratory and field performance of an imidacloprid gel bait against German cockroaches (Dyctioptera: Blattellidae). - J. Econ. Entomol. 93: 112-118.

BONNEFOY S., KAMPEN H., SWEENEY K., 2008 - Public health significance of urban pests. World Health Organization, Copenhagen: pp. 569.

BUCZKOWSKI G., SCHAL C., 2001a - Method of insecticide delivery affects horizontal transfer of Fipronil in the German cockroach (Dictyoptera: Blattellidae). - J. Econ. Entomol. 94: 680-685.

BUCZKOWSKI G., SCHAL C., 2001b - Emetophagy: Fipronilinduced regurgitation of bait and its dissemination from German cockroach adults to nymphs. Pestic. Biochem. Phys. 71: 147-155.

DURIER V., RIVAULT C., 2000 - Secondary transmission of toxic baits in German cockroach (Dictyoptera: Blattellidae). - J. Econ. Entomol. 93: 434-440.

FOTEDAR R., SHRINIWAS U.B., VERMA A., 1991 Cockroaches (Blattella germanica) as carriers of microorganisms of medical importance in hospitals. - Epidemiol. Infect. 107: 181-187.

GAHLHOFF J.E., MILLER D.M., KOEHLER P.G., 1999 Secondary kill of adult male German cockroaches (Dictyoptera: Blattellidae) via cannibalism of nymphs fed toxic baits. - J. Econ. Entomol. 92: 1133-1137.

GUTHRIE D.M., TINDALL A.R., 1968 - The biology of the cockroach. St. Martins, New York: pp. 408.

JARAMILLO R. G. I., GONZALEZ O. R., 2005 - Muerte secundaria de adultos de Periplaneta americana (Blattodea: Blattidae) vía canibalismo de especímenes muertos por imidacloprid. - Rev. Colomb. Entomol. 31: 5-8.

PAMPIGLIONE G., VELO E., 2010 - Pest management in Albania: un esempio di copartecipazione allo sviluppo tecnicoscientifico in salute pubblica. Veterinaria Italiana 46: 29-35.

ROTH L.R., WILLIS E.R., 1960 - The biotic associations of cockroaches. The Smithsonian Institution, Washington D.C., pp. 470.

RUST M.K., OWENS J.M., REIERSON D.A. [eds.], 1995 Understanding and Controlling the German Cockroach. Oxford University Press, New York/Oxford: pp. 448.

SALEHZADEH A., DAVARI B., DARVISH Z., NASIRIAN H., 2020 - The efficacy of baits containing abamectin, dinotefuran, imidacloprid and pyriproxyfen + abamectin against Blattella germanica (L.) (Blattaria: Blattellidae), the German cockroach. - Afr. Entomol. 28: 225-237. 